\title{
EL ENTIERRO 2 DEL SITIO CAÑADÓN LEONA 5 (REGIÓN DE MAGALLANES, CHILE). VIEJOS HUESOS, NUEVOS DATOS
}

\author{
G. LORENA L'HEUREUX" Y TOMAS AMOROSI"
}

\section{RESUMEN}

En este trabajo se presenta el estudio bioarqueológico de los restos óseos humanos del entierro 2 del sitio Cañadón Leona 5 (Región de Magallanes, Chile) excavado por el arqueólogo norteamericano Junius Bird en la década del '30. Se analizaron tanto los procesos fisiológicos y patológicos como las modificaciones tafonómicas que afectaron los ocho individuos (dos subadultos y seis adultos) identificados en el entierro, actualmente depositados en la División de Antropología del Museo Americano de Historia Natural de Nueva York. La presencia de traumas intencionales por compresión en la bóveda craneana de dos individuos adultos (perforación circular y subcircular con fractura y bordes remodelados) se relacionan con las causas de muerte de los mismos. Estas lesiones se asocian con eventos de violencia interpersonal dentro o entre grupos de cazadores-recolectores vecinos (raids?). Esta última opción pudo originarse por competencia por el territorio y sus recursos en un momento del Holoceno tardío (ca. 2.300 años ${ }^{14} \mathrm{C} \mathrm{AP}$.) para el cual se estima un incremento significativo en la densidad poblacional en el área (51-52, $4^{\circ}$ sur).

PALABRAS CLAVES: análisis bioarqueológico; cazadores-recolectores; violencia interpersonal; Holoceno tardío.

\section{THE BURIAL 2 OF CAÑADÓN LEONA 5 SITE (REGION OF MAGALLANES, CHILE). OLD BONES, NEW DATA}

\footnotetext{
ABSTRACT

In this paper we present a bioarchaeologic study of human remains of burial 2 of Cañadón Leona 5 site (Magallanes, Chile), excavated by the American archaeologist Junius Bird during the 1930s. We examined the 8 individuals (2 subadults and 6 adults) recovered in this burial -currently housed at the Anthropology Division, American Museum of Natural History, New York-, from a physiological, pathological, and taphonomic point of view. In this assemblage, two calvaria exhibit compressive traumas (circular and subcircular perforations with some rim remodeling). In both cases it is inferred that these

DIPA-IMHICIHU (CONICET). Saavedra 15, 5 piso (1083 ACA). Buenos Aires, Argentina. E-mail: lorenalheureux@yahoo. com.ar

" Division of Anthropology, American Museum of Natural History. Central Park West, 79th Street, New York. EE.UU.

E-mail: tamorosi@ix.netcom.com
} 
unhealed lesions were related to the cause of death. It could be proposed that the recorded injuries may have been related to interpersonal violence either among or between groups (raids?). The latter case is likely in the context of a higher territorial competence in this area between neighboring hunter-gatherer groups at a time (ca. 2.300 radiocarbon years BP), for which a significant increase in population density has been inferred by means of independent archaeological evidence in the area of study (51-52.4 $\mathrm{S}$ ).

KEY WORDS: bioarchaeologic analysis; hunters-gatherers; interpersonal violence; late Holocene.

\section{INTRODUCCIÓN}

El Cañadón Leona se localiza en la ladera oriental de la Laguna Blanca a $48 \mathrm{~km}$ al noroeste del estrecho de Magallanes en el sector occidental de la Región de Magallanes, República de Chile $\left(52^{\circ}\right.$ 22 ' 4.80" S; 7107' 4.80" W) (Fig. 1). La localidad arqueológica de Cañadón Leona fue descubierta y trabajada por primera vez por el arqueólogo norteamericano J. Bird durante los veranos de 1935 y 1936. El farallón del cañadón presenta cinco aleros, uno con representaciones rupestres (alero 3) y otro con materiales en estratigrafía (alero 5). J. Bird trabajó extensamente el alero número 5 excavando aproximadamente $210 \mathrm{~m}^{3}$. En el mismo recuperó dos entierros humanos, 4914 artefactos líticos, más de 200 instrumentos de hueso e incalculables fragmentos óseos con evidencia antrópica (Bird 1988).
Después de los trabajos de J. Bird, en el sitio 5 de Cañadón Leona se realizaron otras excavaciones. Un equipo francés a cargo de A. Laming-Emperaire (Laming-Emperaire 1968) excavó el alero durante los veranos de 1961 y 1962, y en 1970 el arqueólogo chileno O. Ortíz-Troncoso realizó un sondeo por fuera de la línea de goteo del alero. Lamentablemente en ambos casos la información detallada de estas excavaciones y de los materiales recuperados no fue publicada. Finalmente, en los veranos de 1995 y de 1997 otro equipo chileno del Instituto de la Patagonia, Universidad de Magallanes, excavó en el alero 5 dos cuadrículas de $1 \mathrm{~m}^{2}$ de profundidad en un sector próximo al trabajado por J. Bird, alcanzando los 2 $\mathrm{m}$ de profundidad (Prieto et al. 1998). El objetivo de estas nuevas excavaciones fue otorgarle un marco cronológico absoluto al sitio, ya que el mismo no poseía dataciones radiocarbónicas.

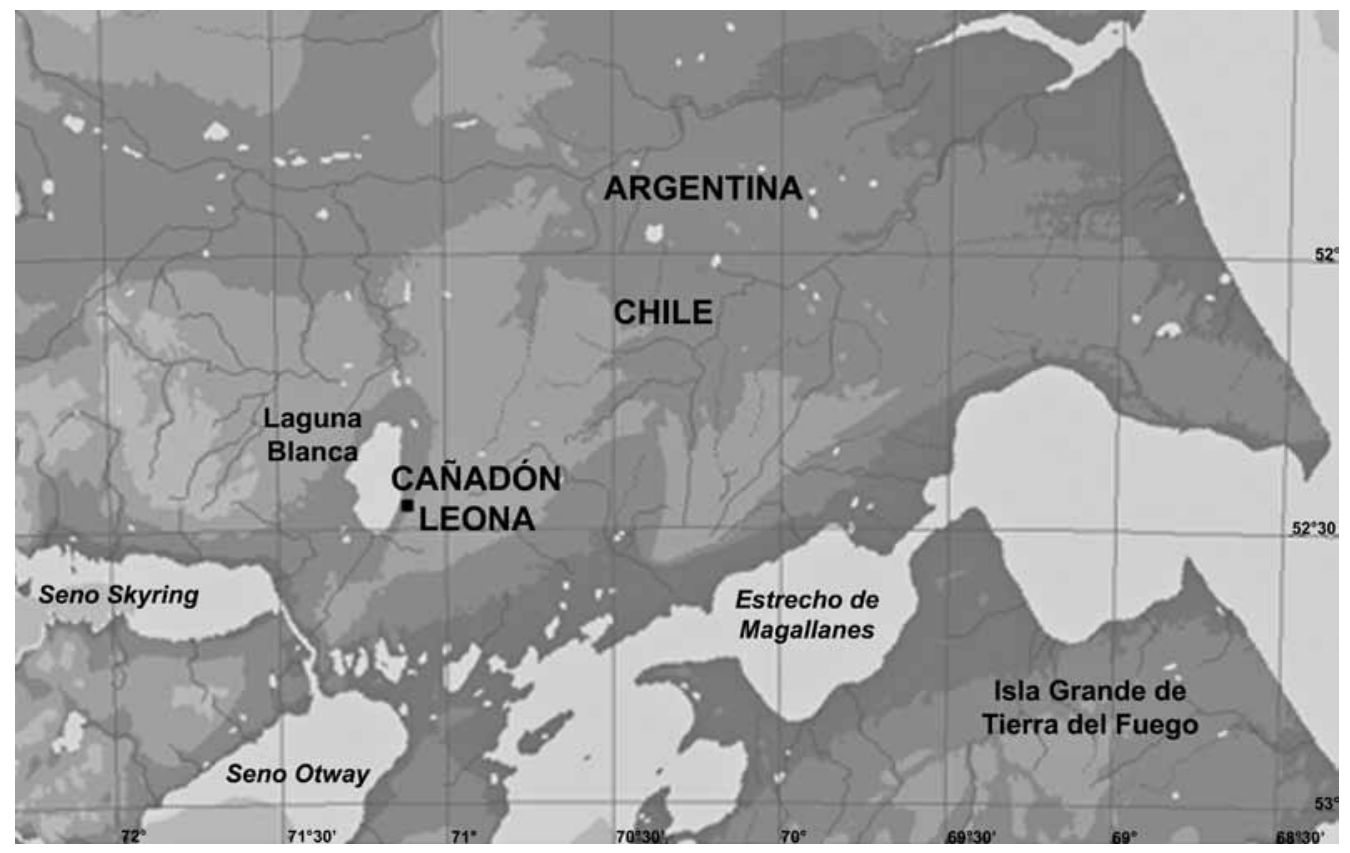

Fig. 1. Localización del sitio Cañadón Leona 5. 
Durante sus trabajos de campo en el sitio 5 de Cañadón Leona, J. Bird recupera dos entierros múltiples separados entre sí por 5,47 m de distancia. Debido a que la información descriptiva relacionada con la excavación y los restos óseos del entierro 1 se perdieron, en este trabajo se estudian sólo los esqueletos humanos procedentes del entierro 2 que actualmente se encuentran depositados en la División de Antropología del Museo Americano de Historia Natural de Nueva York (AMNH).

De acuerdo con los datos contextuales brindados por J. Bird, la inhumación múltiple se hallaba en una cavidad de $50,8 \mathrm{~cm}$ de profundidad, $152,4 \mathrm{~cm}$ de largo y 91,44 cm de ancho (Bird 1988:62) en el piso de la capa 10 de la excavación, aproximadamente a unos 228,5 cm de profundidad (Bird 1988: Fig. 21). Los esqueletos se encontraron en su mayoría articulados en posición anatómica aunque incompletos, registrándose in situ el desplazamiento de diferentes elementos debido a la inclinación del terreno (e.g. el cráneo del individuo 3; Bird 1988:64) y a otras modificaciones posdepositacionales. Los individuos fueron ubicados en la fosa de manera superpuesta y dispuestos en posición decúbito lateral izquierdo con los miembros inferiores completamente flexionados y los superiores extendidos y juntos hacia la pelvis (Bird 1988: Figs. 25 y 26; Fig. 2).

Los trabajos de excavación se complicaron debido a que en ese momento la capa freática se encontraba aproximadamente a $76 \mathrm{~cm}$ de profundidad, muy por encima del nivel de los entierros. J. Bird menciona la inundación total y constante de la excavación y los esfuerzo de extracción del agua mediante incansables trabajos con baldes y la construcción de una trinchera de $381 \mathrm{~m}$ de longitud para su desagüe (Bird 1988:39-40). Sin duda esta situación debió complicar, además de los trabajos de excavación, el registro contextual del entierro ya que al escurrir tanta agua por el canal siguiendo la inclinación natural de la superficie, se debió promover el desplazamiento de elementos y/o la modificación de las relaciones anatómicas esqueletales originales.

\section{Consideraciones cronológicas}

En un principio, haciendo inferencias sobre la uniformidad del sedimento y la profundidad alcanzada por las carcasas de Ovis aries que se depositaron naturalmente en la superficie del alero, J. Bird in-

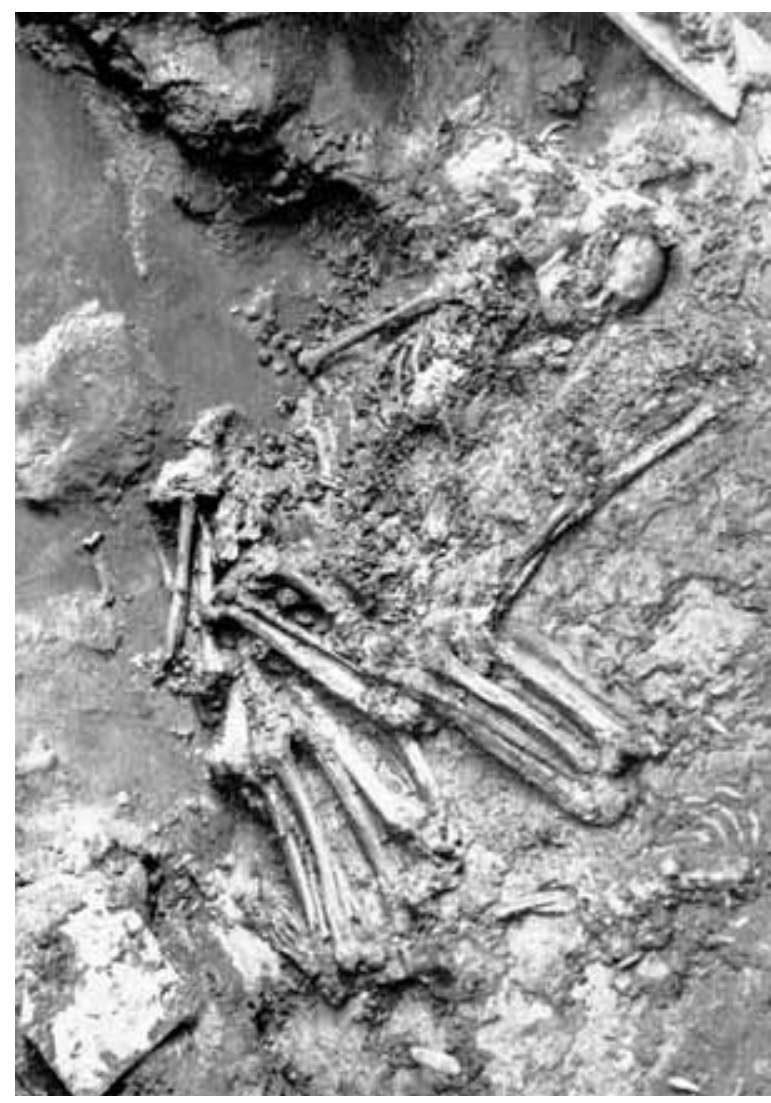

Fig. 2. Excavación del entierro 2. Disposición y orientación de los individuos. Imagen tomada de J. Bird (1988: fig. 25).

fiere una antigüedad aproximada de 1480 a 1655 años AP. para el sitio (Bird 1988:61-62). Pero, por otro lado, cuando el autor evalúa la posible cronología de los entierros, asocia los mismos con los cazadores-recolectores característicos del Período III de la secuencia cronológica-cultural de la cueva Fell, agregando que los cuerpos debieron ser inhumados al final de dicho período (Bird 1988:65). Entonces, haciendo una correlación entre Cañadón Leona 5 con los hallazgos que caracteriza al mencionado Período de Fell, el autor le otorga a los entierros del sitio una antigüedad aproximada de $6.740 \pm 130-$ $6.385 \pm 115$ años AP. (final Período III Cueva Fell; Tabla 17 en Bird 1988:187).

Actualmente se conoce que esta inferencia cronológica es errónea y que, por el contrario, la edad de 1.480 a 1.655 años AP. que Bird sugiere inicialmente se ajusta más con las dataciones absolutas obtenidas posteriormente por A. Prieto y colegas (Prieto et al. 1998). Este equipo de arqueólogos obtuvo cuatro 
Tabla 1. Fechados radiocarbónicos del sitio Cañadón Leona 5. Edades no calibradas.

\begin{tabular}{|c|c|c|c|c|c|}
\hline PROCEDENCIA & UNIDAD & PROFUNDIDAD & EDAD & MUESTRA & REFERENCIA \\
\hline & XV & $140-150 \mathrm{~cm}$ & $2.130 \pm 80$ & carbón vegetal & Prieto et al. 1998 \\
Cuadrícula & XVII & $160-170 \mathrm{~cm}$ & $1.740 \pm 70$ & carbón vegetal & Prieto et al. 1998 \\
A4 & XVIII & $170-180 \mathrm{~cm}$ & $2.270 \pm 50$ & carbón vegetal & Prieto et al. 1998 \\
& XX & $190-200 \mathrm{~cm}$ & $2.280 \pm 60$ & carbón vegetal & Prieto et al. 1998 \\
\hline
\end{tabular}

dataciones a partir de muestras de carbón vegetal de fogones hallados en los niveles XV, XVII, XVIII y $\mathrm{XX}$ de la cuadrícula A4 de la excavación realizada en el sitio durante 1995 y 1997 (Tabla 1). Las edades obtenidas exponen una secuencia cronológica que permite ubicar temporalmente con mayor precisión a Cañadón Leona 5 entre $1.740 \pm 70$ y $2.280 \pm$ 60 años AP. Teniendo en cuenta la profundidad de la depositación del entierro 2 definida por J. Bird (Nivel 10:228,5 cm; Bird 1988: Fig. 21) el mismo se encontraría apenas por debajo del nivel XX datado $(210 \mathrm{~cm})$ por Prieto y colaboradores (1998), por lo cual se estima que los entierros se ubicarían en el Holoceno tardío aproximadamente entre el 2.300 y 2.500 años AP. Igualmente, esta fecha deberá ser contrastada con dataciones futuras obtenidas directamente de los huesos humanos.

\section{El entierro 2 de Cañadón Leona 5.}

Composición y descripción

Los esqueletos procedentes del entierro 2 ingresaron al AMNH con cuatro números de catálogo (99.1/68 a 99.1/771) y más de un individuo fue identificado con el mismo rótulo. Siguiendo las variaciones en la maduración ósea, tamaño y robustez, pudieron separarse varios individuos entre los elementos con igual número de catálogo. Por suerte, se observaron notables diferencias de sexo, edad y conservación que facilitaron esta tarea.

Bird menciona que en el sitio se hallaron ocho individuos compuestos por siete adultos y uno subadulto (Bird 1988:62), mientras que en laboratorio se identificaron 8 individuos en total pero sólo seis individuos son adultos y dos son subadultos (Tabla 2). Este trabajo no tiene como objetivo destacar las coincidencias y discordancias entre las notas de campo y el material que definitivamente fue ingresado en la colección del AMNH producto de la excavación, por lo cual en adelante se trabaja con la estructura etaria y sexual identificada por los autores.

En general, los esqueletos se encuentran incompletos y con una conservación regular. El individuo CL.1.1 (99.1/769) es un individuo masculino adulto joven. El sexo y la edad se estimaron a partir de los rasgos presentes en pelvis y cráneo (Buikstra y Ubelaker 1994; Meindl y Lovejoy 1985). La edad estimada fue de ca. 31 años por la superficie auricular en pelvis y de 20-30 por la erupción y oclusión dental completa (que ya presenta facetas de desgaste en el $\mathrm{M}_{3}$ ), por lo que su edad se promedió en 23-27 años. CL1.1 está representado por un NISP de 244 especímenes y un MNE de 53 elementos del esqueleto axial (cráneo, mandíbula,

Tabla 2. Estructura sexual y etaria de la muestra y especímenes identificados por individuo.

\begin{tabular}{|c|c|c|cc|c|}
\hline & SEXO & \multicolumn{1}{|c|}{ EDAD } & NISP \\
\hline CL.1.1 & AMNH.99.1/769 & M & Adulto joven & $23-27$ años & 244 \\
CL.1.2 & AMNH.99.1/769 & $\mathrm{F}$ & Adulto joven & $20-25$ años & 244 \\
CL. 2.1 & AMNH.99.1/770 & M & Adulto joven/medio & $33-37$ años & 182 \\
CL.2.2 & AMNH.99.1/770 & F & Adulto medio & INDET. & 72 \\
CL.3 & AMNH.99.1/771 & F & Adulto medio & $35-40$ años & 182 \\
CL.4.1 & AMNH.99.1/768 & F? & Adulto medio & $35-40$ años & 9 \\
CL.4.2 & AMNH.99.1/768 & INDET & Subadulto & $>10$ años & 2 \\
CL.4.3 & AMNH.99.1/768 & M? & Subadulto & $14-16$ años & 7 \\
\hline CL.5 & CDLL 52794 y 52796* & INDET & Adulto & INDET. & 2 \\
\hline
\end{tabular}

Individuo formado por dos gérmenes de molares (coronas incompletas) catalogados como 768 y 770 que podrían corresponder al mismo subadulto (menor de 10 años).

* Restos humanos adicionales (Prieto et al. 1998:90) depositados en el Centro de Estudios del Hombre Austral, Instituto de la Patagonia, Universidad de Magallanes, Chile. 
Tabla 3. Medidas poscraneales de los individuos de Cañadón Leona 5. La numeración refiere a la descripción de las medidas en Buikstra y Ubelaker (1994).

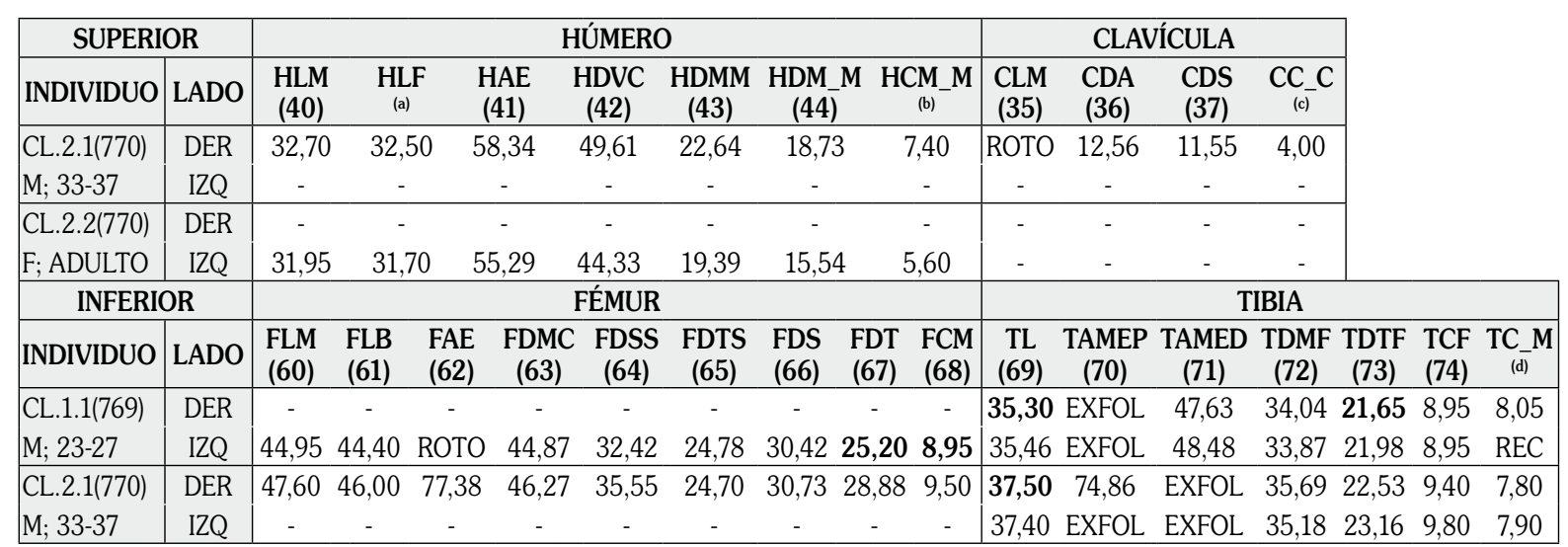

(a)HLF: longitud fisiológica. Desde el punto más superior de la cabeza del húmero hasta el cóndilo humeral; () HCM_M: circunferencia mínima, por debajo de la inserción deltoidea (con cinta); ${ }^{(c)}$ CC_C: circunferencia al medio de la diáfisis de la clavícula; (d)TC_M: circunferencia mínima de la tibia (con cinta); ROTO: eliminación ósea posdepositacional; EXFOL: muy exfoliado; REC: reconstruido y modificado. En negrita: medidas tomadas con proyección por exfoliación.

vértebras dorsales y dos lumbares) y apendicular (huesos de la mano y del pie, pelvis, ulnas, húmero derecho, radio y fémur izquierdo, tibias) denotando una elevada fragmentación posdepositacional. De todos modos se pudo medir el fémur izquierdo y las tibias (Tabla 3). A partir de las fórmulas de regresión de estimación de la estatura máxima en vida desde las longitudes totales de los huesos largos de mongoloides masculinos (Trotter 1970 en Steele y Bramblett 1988), se derivó una estatura de 169,21 $\pm 3,8 \mathrm{~cm}$ a partir del fémur izquierdo y de 166,21 $\pm 3,27 \mathrm{~cm}$ desde la tibia izquierda para CL1.1.

El individuo CL.1.2 (99.1/769) femenino de 20-25 años se compone principalmente por elementos del esqueleto axial (calvaria y vértebras cervicales e indeterminadas), algunos huesos del pie, escápulas, húmeros, ulna derecha y un fragmento de tibia derecha y fémur indeterminado representando 26 elementos y 244 especímenes. El NISP se incrementa, además por la elevada fragmentación y las abundantes misceláneas no identificadas, por las piezas dentales del maxilar aisladas que se cuantificaron por separado (NISP: 10). La edad y el sexo se estimaron a partir de los rasgos observables en la calvaria (Buikstra y Ubelaker 1994; Meindl y Lovejoy 1985).

El individuo CL.2.1 (99.1/770) es masculino adulto joven/medio de aproximadamente 33-37 años de edad al momento de muerte. El sexo se estimó a partir de indicadores en cráneo y pelvis (Buikstra y
Ubelaker 1994) y para la edad se promedió aquella obtenida a partir de la sínfisis púbica y la superficie auricular y la observada en la calvaria (Brooks y Suchey 1990; Meindl y Lovejoy 1985). Se analizaron 182 especímenes de 44 elementos apendiculares (huesos de las manos y los pies, húmero derecho, ulnas, radios, fémures, tibias y fíbulas), escápulas, clavículas, pelvis y una subrepresentación de elementos axiales (cráneo, primeras costillas y un único fragmento de vértebra indeterminada). Se midió el húmero derecho, la clavícula derecha, el fémur derecho y las tibias (Tabla 3). La estatura estimada para CL2.1 es de $170,86 \pm 4,25 \mathrm{~cm}$ a partir del húmero, de 174,91 $\pm 3,8$ desde el fémur y de $171,09 \pm 3,27 \mathrm{~cm}$ por la tibia derecha (datos de mongoloides; Trotter 1970 en Steele y Bramblett 1988).

El individuo CL.2.2 es femenino y se compone por 41 elementos compuestos principalmente por huesos de las manos y los pies, mandíbula, radios, húmeros y fragmentos de escápula, fémur y fíbula izquierda en relativo buen estado de conservación y con menor fragmentación respecto de los individuos antes descriptos (NISP:72). Por la ausencia de bóveda craneana y pelvis no pudo evaluarse la edad aunque se estima se trata de uno de los individuos de mayor edad del conjunto de acuerdo con la presencia de modificaciones degenerativas bucales asociadas con el avance de la edad (enfermedad periodontal y pérdidas dentales antemortem; ver infra). Sólo se pudo medir el húmero izquierdo (Tabla 3) y, de acuerdo 
con la ecuación de regresión definida para estimar la estatura máxima en vida desde la longitud total de este hueso (datos mongoloides, Trotter 1970), se obtuvo una estatura aproximada de 168,82 \pm 4,25 $\mathrm{cm}$ para CL.2.2.

El número de catálogo 99.1/771 incluye un MNE aproximado de 19 elementos con elevada fragmentación (NISP:182) y un estado de conservación de regular a malo que pertenecen a un único individuo: CL.3 el cual está representado principalmente por elementos del esqueleto axial (vértebras cervicales, dorsales y lumbares, sacro, esternón y calvaria), el pubis izquierdo y ningún hueso largo. La estimación de la edad se promedió entre la observada en el pubis y la calvaria (35-40 años; Brooks y Suchey 1990; Meindl y Lovejoy 1985). A partir de los rasgos morfológicos en la calvaria (Buikstra y Ubelaker 1994) se identificó que CL.3 es de sexo femenino.

CL.4.1 es un adulto compuesto sólo por un fragmento de mandíbula y otro de maxilar con seis piezas dentales superiores y una inferior aisladas (NISP:9). Debido a la ausencia de indicadores confiables, la edad aproximada se derivó en base al desgaste dental por lo que se estima tendría poco más de 35 años de edad. Para esto se utilizaron comparativamente los grados y tasas de desgaste de poblaciones cazadoras-recolectoras de áreas adyacentes con una cronología semejante, e.g. Orejas de Burro 1 y Cerro Sota (L'Heureux y Amorosi 2009 y L'Heureux Barberena 2008). Los elementos presentes no alcanzan para obtener información confiable relacionada con el sexo, pero la morfología de la sínfisis de la mandíbula es asimilable a una de sexo femenino (Buikstra y Ubelaker 1994).

El individuo CL4.2 (Tabla 2), se compuso por dos piezas dentales aisladas (gérmenes de molares) catalogados con números diferentes (99.1/768 y $99.1 / 770)$ y que no podían ser de ninguno de los individuos adultos identificados bajo los números originales. Tampoco corresponden al individuo subadulto 99.1/768 que posee sus molares desarrollados y en oclusión, por lo que se trataría de otro individuo inmaduro de menor edad. Como no pudo identificarse si los gérmenes permanentes eran de un primer o segundo molar, se decidió definir este individuo como menor de 10 años.

El subadulto CL.4.3 se compone sólo por un fragmento del cráneo (foramen magnum) y

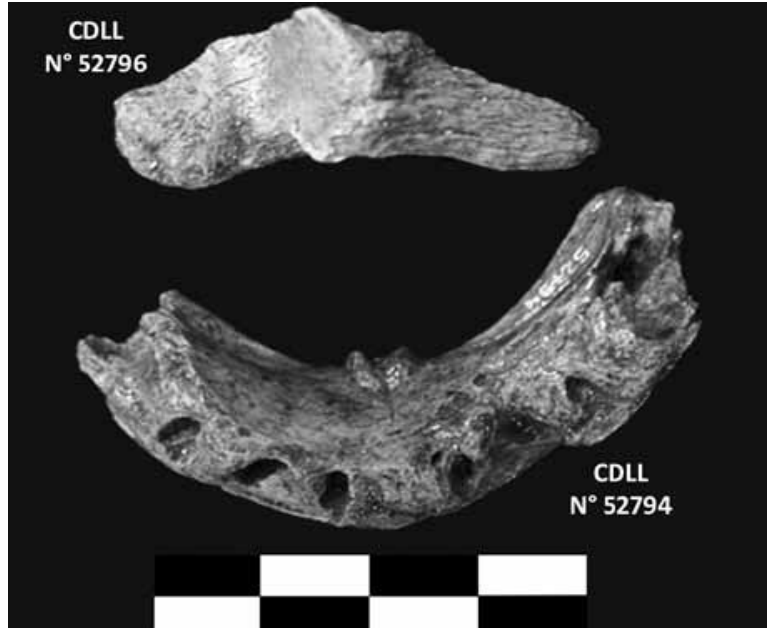

Fig. 3. Elementos óseos humanos adicionales recuperados en 1997 en el sitio Cañadón Leona 5 (Prieto et al. 1998) y depositados en el Centro de Estudios del Hombre Austral, Instituto de la Patagonia, Universidad de Magallanes.

Imágenes cedidas por A. Prieto y S. Morano Büchner.

otro de mandíbula (ángulo mandibular derecho) y cinco piezas dentales aisladas (con tres dientes anteriores que presentan morfología en pala). No hay elementos con información que permita hacer una buena estimación del sexo y edad, pero teniendo en cuenta la erupción del $\mathrm{M}^{2}$ (ca. $12 \pm$ 36 meses; Ubelaker 1989) y su bajo desgaste, se estima que este molar estuvo en oclusión relativamente poco tiempo considerando una elevada tasa de desgaste entre cazadores recolectores (ca. alrededor de 15 años). El ángulo y eversión del gonio mandibular tendría una morfología asimilable con aquella identificada en individuos masculinos (Schutkowski 1993).

A este conjunto debe agregarse que durante las excavaciones realizadas por el equipo chileno en 1995/97 (Prieto et al. 1998), se hallaron otros restos óseos humanos a $190-200 \mathrm{~cm}$ de profundidad en la cuadrícula A4 localizada al oeste del sector excavado por J. Bird (Tabla 2). Este material (agrupado en un único individuo denominado CL.5) incrementa el MNI del sitio a 9 individuos y se compone por una sínfisis de mandíbula sin piezas dentales y un fragmento de epífisis proximal de ulna izquierda fusionada y muy exfoliada (Fig. 3). La ausencia de elementos diagnósticos y la fragmentación del material impide una ajustada identificación de los parámetro de edad y sexo de CL.5. 


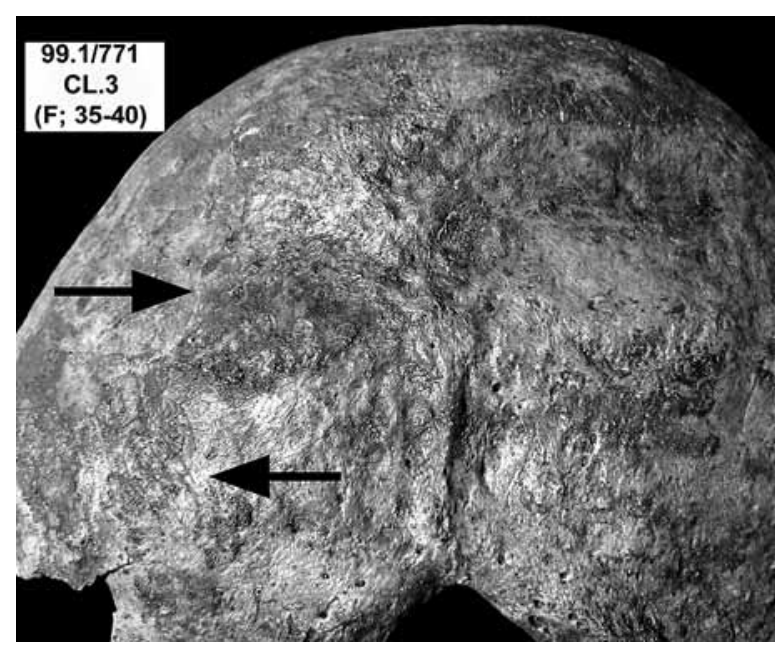

Fig. 4. Rastros discontinuos de ocre en el occipital de CL.3.

\section{Modificaciones pre y posdepositacionales}

De acuerdo con el análisis de las modificaciones predepositacionales antrópicas registradas, el 75\% de los individuos presentaron ocre sobre las superficies corticales en diferentes regiones esqueletales. De todos los especímenes analizados, el 46,07\% se encontró teñido y su prevalencia fue variable según los individuos identificados (Fig. 4). El individuo que más elementos teñidos presenta es CL2.2, un adulto medio femenino (98,61\%), seguido de los individuos adultos CL.1.2 y CL.2.1 (65,57 y 62,64\% respectivamente) y CL.3 y CL.1.1 (28,57 y 14,34\%). Contrariamente con lo registrado en otros sitios de áreas aledañas (e.g. OB.1; LHeureux y Barberena 2008), el individuo subadulto con elementos óseos observables fue uno de los menos tratados (CL.4.3: 28,57\%). La presencia de ocre también se registró en el sedimento circundante (red clay; Bird 1988:62) por lo que se estima que en

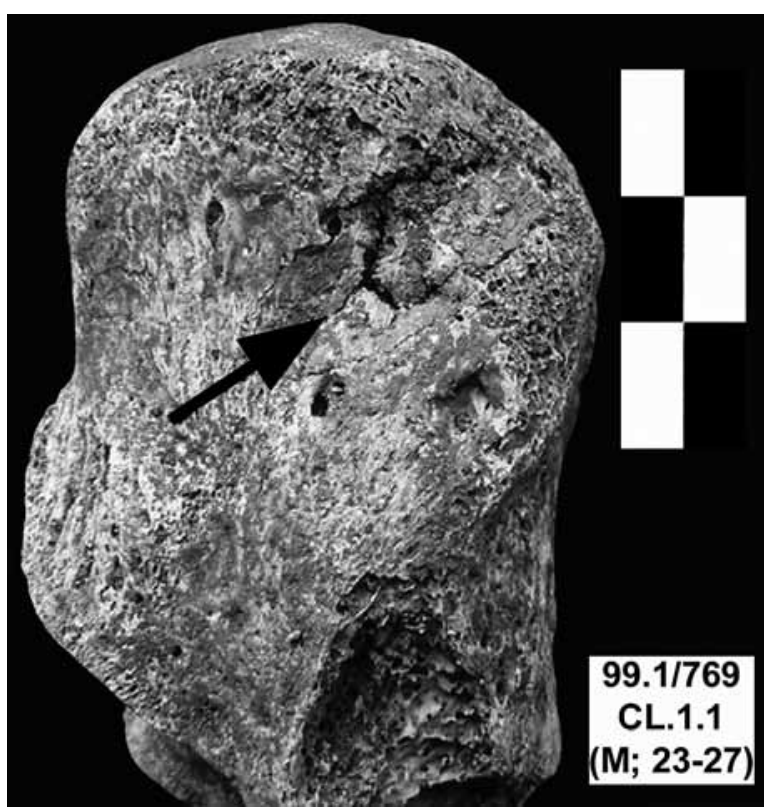

Fig. 5. Calcáneo derecho de CL.1.1. Se observa el hundimiento del tejido compacto con fisuras radiales y pits asociadas con daños mecánicos. El elemento también presenta rastros de ocre en su superficie cortical.

el acto de inhumación los cuerpos fueron tratados directamente con pigmento rojo o envueltos/cubiertos con un material pintado con ocre (e.g. cuero). Entre los elementos analizados no se registra evidencia de combustión de los cuerpos y, de acuerdo con la información contextual recuperada por J. Bird, no se halló ajuar funerario en el entierro.

Las principales modificaciones posdepositacionales registradas se relacionan con la elevada frecuencia de fragmentación (algo atenuada por los esfuerzos de reconstrucción; 70,91\%), y la exfoliación de las superficies corticales, que definen un estado general de conservación regular de los materiales

Tabla 4. Modificaciones tafonómicas observadas en los elementos óseos humanos.

\begin{tabular}{|c|c|c|c|c|c|c|c|}
\hline \multirow{2}{*}{ INDIVIDUO } & \multicolumn{7}{|c|}{ VARIABLES TAFONÓMICAS } \\
\cline { 2 - 8 } & $\mathrm{MnO}_{2}$ & Exfoliación & Raíces & Daño mecánico & Rotura Posdep & $\mathrm{CaCo}_{3}$ & $\begin{array}{c}\mathrm{N} \\
\text { Huesos }\end{array}$ \\
\hline CL.1.1 & 9 & 241 & 19 & 43 & 33 & 0 & 244 \\
CL.1.2 & 1 & 49 & 2 & 5 & 235 & 9 & 244 \\
CL.2.1 & 4 & 84 & 0 & 26 & 163 & 15 & 182 \\
CL.2.2 & 2 & 69 & 2 & 17 & 51 & 2 & 72 \\
CL.3 & 0 & 80 & 2 & 28 & 182 & 6 & 182 \\
CL.4.1 & 0 & 8 & 0 & 0 & 2 & 0 & 9 \\
CL.4.2 & 0 & 0 & 0 & 0 & 0 & 0 & 2 \\
CL.4.3 & 1 & 0 & 0 & 1 & 2 & 0 & 7 \\
\hline TOTAL & 17 & 531 & 25 & 120 & 668 & 32 & 942 \\
\hline
\end{tabular}


(Tabla 4). Por otro lado, es elevada la frecuencia de daños mecánicos (12,74\%). Estos se observan como "pits" acompañados de estrías, fisuras radiales, y/o hundimiento del tejido cortical (Tabla 4) y se asocian con el contacto directo de las superficies óseas con elementos duros con aristas o bordes agudos (Fig. 5). Le siguen las frecuencias de especímenes con carbonato de calcio $\left(\mathrm{CaCO}_{3}: 3,40 \%\right)$, con marcas de radículas $(2,65 \%)$ y tinción con manganeso $\left(\mathrm{MnO}_{2}\right.$ : $1,8 \%$ ). En las notas de campo (Bird 1988) no se informa sobre la presencia de rocas sobre los esqueletos o un sedimento carbonatado, pero su presencia puede inferirse a partir de esta evidencia indirecta.

Dentro de la historia posdepositacional de estos esqueletos no se puede dejar de mencionar el impacto de los procesos tréficos (Hesse y Wapnish 1985) en los materiales recuperados en Cañadón Leona 5. Éstos se asocian con el tratamiento de los huesos una vez excavados y contemplan su traslado, clasificación y las acciones dirigidas a su conservación. De acuerdo con esto, los huesos de Cañadón Leona 5 fueron esmeradamente tratados aunque su resultado, setenta años después, resulte difícil de valuar. El tratamiento de remontaje, reconstrucción y consolidación realizado en los laboratorios del AMNH siguió los estándares consensuados para la época,

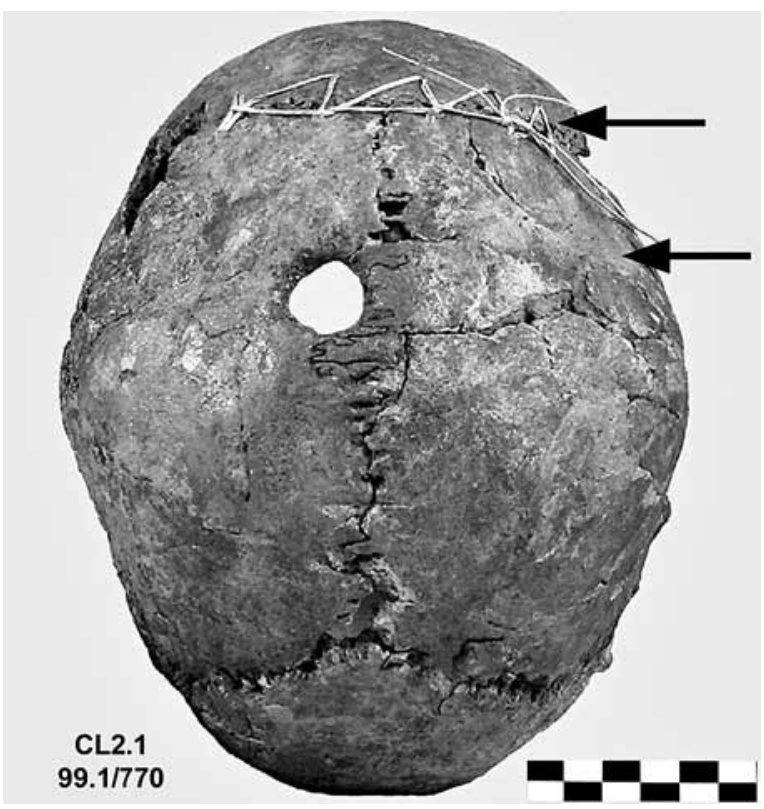

Fig. 6. Procesos tréficos (Hesse y Wapnish 1985). Evidencias de consolidación (Polymetil methacrylato), restauración (pegamento no hidrosoluble) y reconstrucción (plastilina industrial; hilo sisal) en la calvaria de CL.2.1.

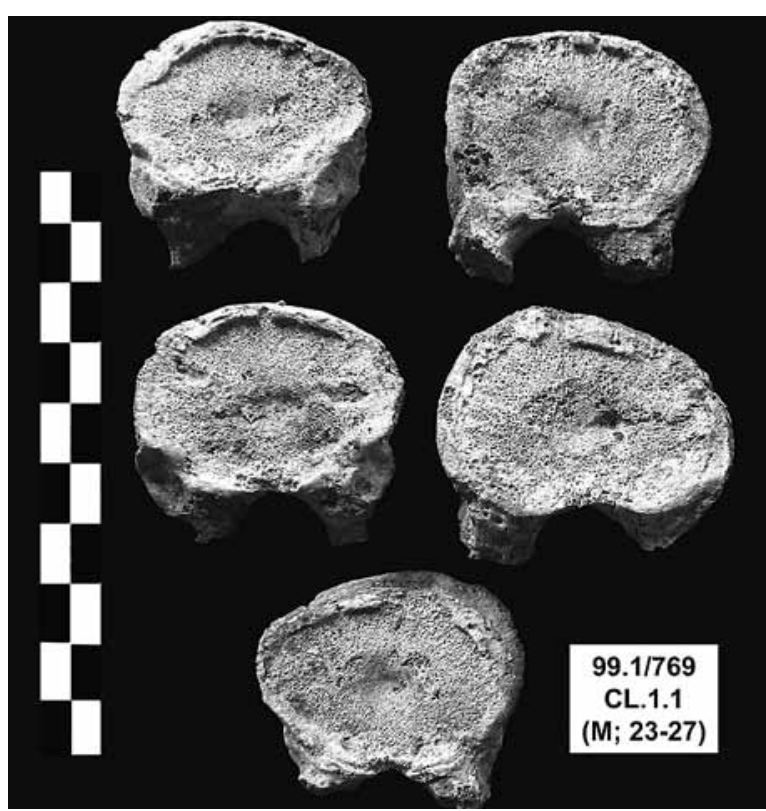

Fig. 7. Nódulos de Shmorld en la superficie craneal de las vértebras dorsales y lumbares de CL.1.1. Esta modificación se asocia con lipping de los bordes de los cuerpos vertebrales.

utilizando plastilina industrial, pegamento, varillas plásticas para las reconstrucciones y polymetil methacrylato disuelto en Xylene para su consolidación.

Resulta importante comentar las acciones de consolidación y reconstrucción a las que fueron sometidas las muestras, ya que estos tratamientos interfirieron en la evaluación y relevamiento de las variables tafonómicas. Sólo como curiosidad, no se puede dejar de mostrar uno de los casos más llamativos donde se utilizó el zurcido de un cráneo con hilo sisal (además de plastilina industrial y una espesa mano de laca) para su reconstrucción (Fig. 6).

\section{Modificaciones fisiológicas y patológicas}

A diferencia de otros entierros humanos excavados por J. Bird en el sur de Chile, el de Cañadón Leona parece ser el que menor interés suscitó a la hora de describirlo o de presentar algún tipo de información derivado del análisis de los huesos en laboratorio. De allí que muchas de las cajas que contenían las muestras de este entierro evidenciaban no haber sido manipuladas por décadas. El estudio de estos huesos produjo información que puede ser relacionada con el tipo de dieta, estado de salud y causas de muerte de los individuos inhumados. 
Tabla 5. Modificaciones patológicas en cráneo y poscráneo de los individuos adultos.

\begin{tabular}{|c|c|c|c|c|c|c|c|c|}
\hline \multirow[b]{2}{*}{ INDIVIDUO } & \multicolumn{4}{|c|}{ DEGENERATIVAS } & \multicolumn{2}{|c|}{ INESPECÍFICAS } & \multirow{2}{*}{\begin{tabular}{|c|} 
TRAUMÁTICAS \\
Fracturas por \\
Compresión \\
\end{tabular}} & \multirow[b]{2}{*}{$\begin{array}{l}\text { Elementos } \\
\text { Afectados }\end{array}$} \\
\hline & $\begin{array}{l}\text { Lipping/ } \\
\text { Osteofitos } \\
\end{array}$ & $\begin{array}{l}\text { Nódulos } \\
\text { Shmorld } \\
\end{array}$ & $\begin{array}{c}\begin{array}{c}\text { Reducción } \\
\text { cuerpo vert. }\end{array} \\
\end{array}$ & Porosidad & $\begin{array}{c}\text { Criba } \\
\text { Orbitalia } \\
\end{array}$ & \begin{tabular}{|c|}
$\begin{array}{c}\text { Hiperostosis } \\
\text { Porótica }\end{array}$ \\
\end{tabular} & & \\
\hline \multirow[t]{2}{*}{$\begin{array}{c}\text { CL.1.1 } \\
\text { 99.1/769 } \\
\text { (M; 23-27) }\end{array}$} & 1 V.Cervical & $\begin{array}{l}12 \text { V.Dorsal }^{a} ; \\
2 \text { V.Lumbar }\end{array}$ & & & & & & \\
\hline & 1 & 14 & 0 & & 0 & 0 & 0 & 15 \\
\hline \multirow[t]{2}{*}{$\begin{array}{c}\text { CL.1.2 } \\
\mathbf{9 9 . 1 / 7 6 9} \\
(\mathrm{F} ; 20-25)\end{array}$} & & & & & Frontal & $\begin{array}{l}\text { Occipital; } \\
\text { Temporal; } \\
\text { Parietal }\end{array}$ & & \\
\hline & 0 & 0 & 0 & & 1 & 3 & 0 & 4 \\
\hline \multirow{2}{*}{$\begin{array}{c}\text { CL.2.1 } \\
99.1 / 770 \\
\text { (M; 33-37) }\end{array}$} & Radio; Ep px & & & & & & Parietal & \\
\hline & 1 & 0 & 0 & & 0 & 0 & 1 & 2 \\
\hline \multirow[t]{2}{*}{$\begin{array}{c}\text { CL.3 } \\
99.1 / 771 \\
\text { (F; 35-40) }\end{array}$} & $\begin{array}{l}3 \text { V.Cervical }^{b} \\
1 \text { V.Lumbar } \\
1 \text { V.Lumbar }\end{array}$ & & $\begin{array}{l}4 \text { V.Cervical } \\
9 \text { V.Dorsal } 1 \\
\text { V.Lumbar }\end{array}$ & $\begin{array}{c}3 \text { V.Cervicald } \\
1 \text { V. Dorsal }\end{array}$ & & & $\begin{array}{l}\text { Parietal; } \\
\text { Temporal }\end{array}$ & \\
\hline & (4) 1 & 0 & 14 & (3) 1 & 0 & 0 & 2 & 18 \\
\hline
\end{tabular}

a: con lipping; ${ }^{\text {b: }}$ con disminución de la altura del cuerpo vertebral y porosidad; c: con disminución de la altura del cuerpo vertebral; ${ }^{\text {d: }}$ con disminución de la altura del cuerpo vertebral y lipping.

En la tabla 5 se observa la presencia y distribución de patologías traumáticas, degenerativas $e$ inespecíficas entre los individuos analizados. En el individuo CL.1.1 (99.1/769) se observaron 15 vértebras con diferentes modificaciones degenerativas y patológicas. Todas las vértebras dorsales y la $4^{\circ} \mathrm{y}$ $5^{\circ}$ vértebra lumbar registraron nódulos de Shmorld producto de la presión del disco interbretebral en las superficies superiores de los cuerpos vertebrales (Fig. 7). Además estos nódulos se encontraron asociados con otros cambios degenerativos (e.g. lipping) en las vértebras dorsales y en los únicos cuerpos de vértebras lumbares halladas.

El individuo adulto más joven identificado CL.1.2 (99.1/769) no presentó modificaciones fisiológicas/patológicas vertebrales en los 12 cuerpos cervicales y en las 4 epífisis de huesos largos presentes. Por otro lado, registró evidencias de una anemia activa por deficiencia de hierro en el occipital, el temporal izquierdo y del parietal derecho (hiperostosis porótica) (Fig. 8) y en la órbita izquierda (criba orbitalia) observable a pesar de la fragmentación y el producto aplicado para la conservación del material. Estas enfermedades se producen por la deficiencia de hierro y pueden relacionarse con carencias nutricionales, parasitosis, infecciones o inapropiada absorción de hierro por trastornos metabólicos (origen inespecífico; Ortner 2003).
CL.2.1 (M; $35 \pm 2$ ) (99.1/770) registra una modificación artrósica (osteofitos y alteración del contorno articular; Waldrom 2009) en la epífisis proximal del radio izquierdo. Los elementos con los que articula la epífisis afectada se encuentran ausentes, igualmente no se registraron modificaciones semejantes en otros huesos largos del mismo u otro lado. Lo más llamativo en este individuo se relaciona con un orificio circular de 15,56 x 12 mm

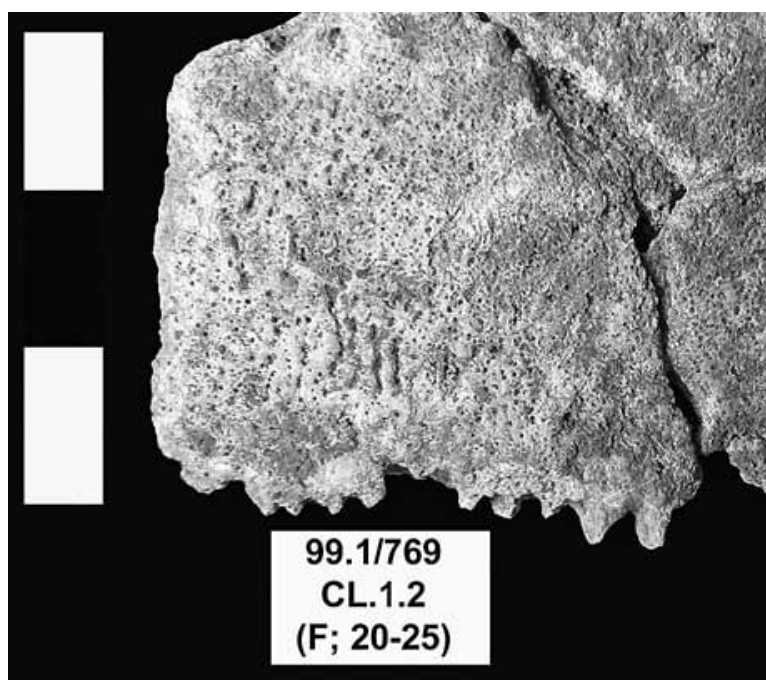

Fig. 8. Evidencia de hiperostosis porótica producida por una deficiencia de hierro activa en vida observable en un fragmento del parietal derecho de CL.1.2. 


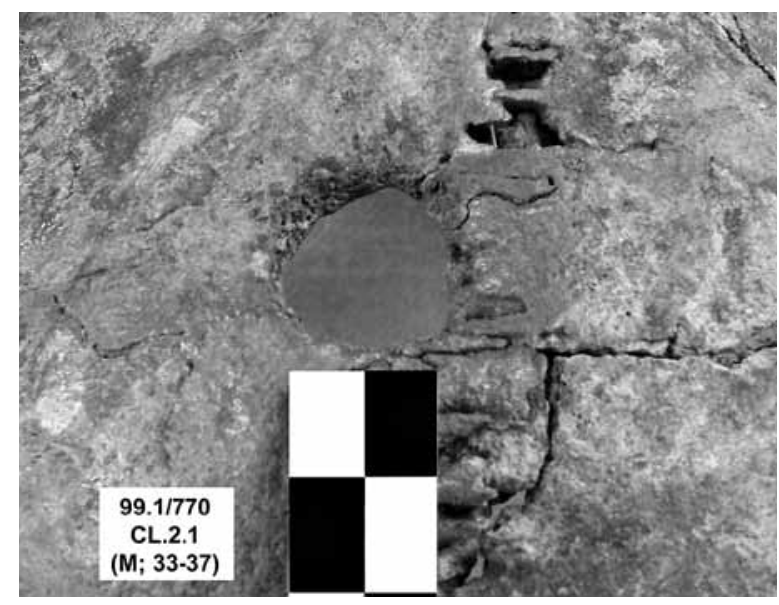

Fig. 9. Fractura traumática por compresión con morfología circular y compromiso total de la tabla externa e interna del parietal izquierdo de CL2.1. Se observa una leve remodelación ósea en el borde de la perforación.

ubicado a un lado de la sutura sagital sobre el parietal izquierdo producto de una fractura por compresión (Ortner 2003). En este caso se observa el completo compromiso de la tabla interna y externa del hueso compacto ocasionando la depresión circular con perforación de la bóveda craneana. Los bordes de esta perforación presentan una remodelación ósea por lo que se infiere que este trauma se produjo un tiempo antes del deceso del individuo. Por localizarse en un lugar vital, sus dimensiones y la mínima remodelación ósea, se considera que dicha lesión pudo generar las complicaciones que culminaron con la muerte de CL.2.1 (Fig. 6 y 9). Debe mencionarse que este cráneo se encuentra restaurado y consolidado pero las técnicas utilizadas no impidieron la observación de la fractura y de sus bordes remodelados en la cara externa como interna del parietal.

En el adulto mayor CL.3 (99.1/771) se encontraron afectadas 18 vértebras en total. Todas las cervicales y dorsales halladas registran la reducción de la altura del cuerpo vertebral. A su vez, las cervicales y las dos lumbares presentan la formación de osteofitos y lipping en los bordes de los cuerpos vertebrales. Estas modificaciones se asocian con enfermedades degenerativas que aparecen con el avance de la edad pero no necesariamente se relacionan con osteoartrosis (Waldron 2009). Pero al tener en cuenta que, además de las modificaciones mencionadas, las vértebras cervicales y la primera vértebra dorsal registran abundante porosidad en la superficie superior del cuerpo, se puede inferir una incipiente enfermedad artrósica por lo menos en la región cervical (Waldron 2009). Al igual que con el individuo CL.2.1, la calvaria de CL.3 presenta una lesión traumática extensa por compresión (Ortner 2003) que compromete el parietal y el temporal derecho (tabla externa e interna). En este caso se observa una depresión subcircular abierta a la altura de la sutura sagital del parietal derecho donde se habría producido el impacto. Desde esta cavidad se origina una fractura que recorre todo el parietal y parte del temporal derecho. Esta lesión denota una remodelación tanto en el centro de la depresión como en la fractura originada en la misma. Aunque la regeneración ósea observada implica un tiempo de supervivencia al impacto (antemortem), la perforación no alcanzó a obliterarse en ningún punto. $\mathrm{Al}$ igual que en el caso anterior, se infiere que esta extensa herida no curada en la bóveda craneana ocasionada por un importante impacto, se relaciona con la causa de muerte del individuo (Figs. 10 y 11).

Se pudo evaluar el grado de desgaste dental sólo en tres individuos adultos (CL.1.1, CL.1.2, CL.4.1)

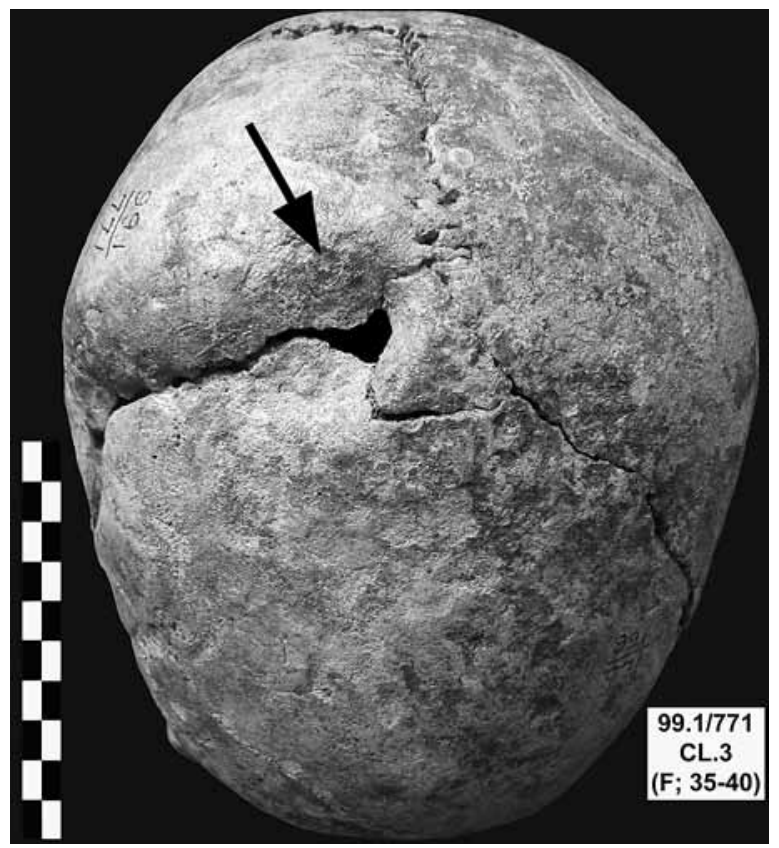

Fig. 10. Lesión traumática compleja por compresión en la calvaria de CL.3. En el sector superior del parietal izquierdo a la altura de la sutura sagital se observa una depresión subcircular con pérdida ósea en el centro donde se origina una fractura que comprende el parietal y temporal izquierdo. Se registra una notable remodelación ósea en la cavidad del centro de la depresión y en los bordes de la fractura. 


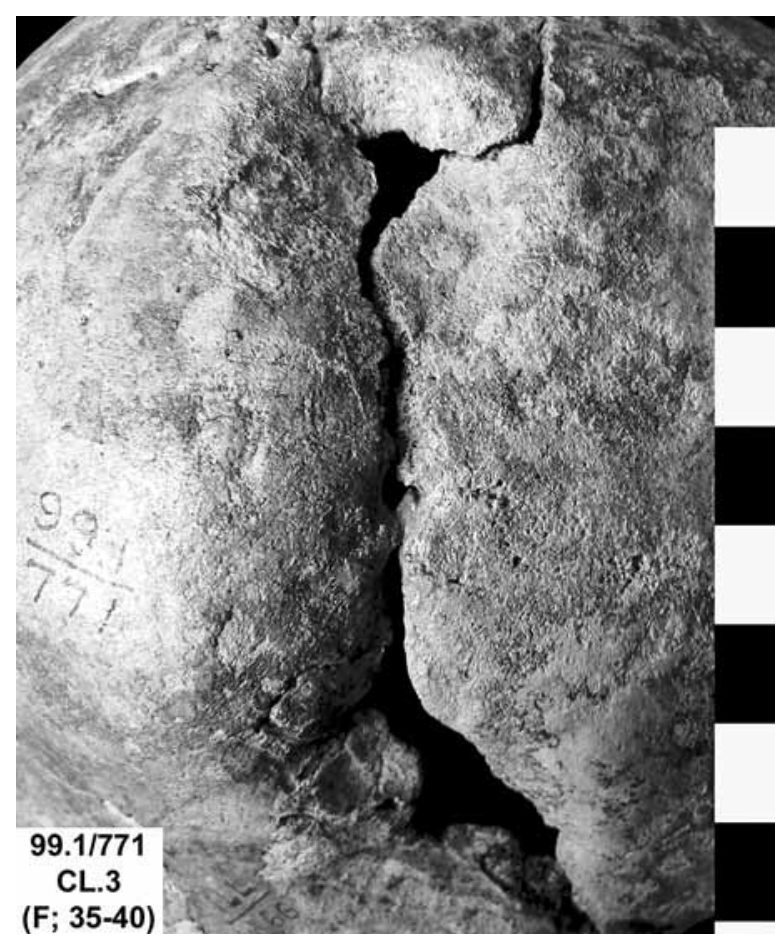

Fig. 11. Vista lateral izquierda de la lesión traumática por compresión de la calvaria de CL.3. Se observa la depresión subcircular con perforación del hueso compacto y la fractura que se origina desde el centro de la misma que recorre todo el parietal y el temporal con pérdida ósea y remodelación de los bordes.

y en un subadulto (CL.4.3). En CL.1.1 y CL.1.2 la edad se derivó por indicadores independientes $\mathrm{y}$, teniendo en cuenta el grado de desgaste observado, mostraron un elevado grado de desgaste dental para la edad estimada, lo cual es esperable para grupos cazadores-recolectores (Tabla 6). En cambio en los individuos CL.4.1 y CL.4.3 se utilizó la secuencia de erupción dental y el desgaste como herramienta de estimación etaria.
Las patologías y modificaciones fisiológicas se evaluaron teniendo en cuenta las prevalencias por individuo y diente o alvéolo. De los ocho individuos se estudiaron sólo cinco maxilares y tres mandíbulas con 54 piezas dentales, denotando una elevada prevalencia de pérdida dental posdepositacional (47,79\%; Tabla 7). Entre las piezas dentales estudiadas no se observaron patologías cariosas. Se registró un solo individuo con dos abscesos furcales (Clarke y Hirsch 1991) marcando una moderada prevalencia de abscesos por individuo (14,27\%) y por alvéolos observados (2,82\%). Los abscesos furcales se definen como daño alveolar limitado al sector óseo en la bifurcación radicular (en molares) (Clarke y Hirsch 1991).

La enfermedad periodontal, una degeneración intermitente de los tejidos de soporte del diente que alcanza el hueso alveolar (Hildebolt y Molnar 1991), se registró levemente en la mandíbula de un único individuo: CL.2.2 (14,27\%; Tabla 7). En este caso se observó una modificación de la morfología normal del hueso alveolar, porosidad del hueso cortical y osteoporosis en el septum interdental en la región de los terceros molares y del $\mathrm{C}$ e $\mathrm{I}_{2}$ derechos (5,63\%; Fig. 12).

Las pérdidas dentales antemortem (PDAM) afectaron trece alvéolos (18,31\%) de tres individuos (42,86\%; Tabla 7). Las PDAM son aquellas pérdidas de piezas dentales que ocurren durante el transcurso de la vida de un individuo, las cuales se consideran de importancia en tanto se relacionan con las presiones masticatorias y la presencia de patologías orales en la población. La exposición de la pulpa y su necrosis, seguida por osteítis periapical y reabsorción alveolar, son comúnmente los pasos que conducen a la PDAM (Lukacs, 1989). En grupos con bajas prevalencias de caries, los dientes se pierden, generalmente, debido

Tabla 6. Desgaste oclusal (Scott 1979; Smith 1984) de los individuos adultos con dientes in situ o aislados observables.

\begin{tabular}{|c|c|c|c|c|c|c|c|c|c|c|}
\hline & & \multicolumn{9}{|c|}{ Maxilar Superior } \\
\hline & $\begin{array}{l}\text { CATEGORÍA } \\
\text { EDAD }\end{array}$ & AÑOS & M3 & M2 & M1 & Pm2 & Pm1 & C & I2 & I1 \\
\hline CL.1.2 & ADULTO JOVEN & $20-25$ & 12 & 16 & 21,5 & 4 & 4,5 & 5 & 6 & 6 \\
\hline CL.4.1 & ADULTO MEDIO & $35-40$ & --- & 23 & 37 & 6 & 6,5 & 6 & 5 & --- \\
\hline \multirow[t]{3}{*}{ CL.4.3 } & SUBADULTO & $14-16$ & --- & 12 & 19 & --- & --- & 3 & 4 & 3 \\
\hline & & \multicolumn{9}{|c|}{ Mandíbula } \\
\hline & $\begin{array}{l}\text { CATEGORÍA } \\
\text { EDAD }\end{array}$ & AÑOS & M3 & M2 & M1 & Pm2 & Pm1 & C & I2 & I1 \\
\hline CL.1.1 & ADULTO JOVEN & $23-27$ & 12 & 17 & 23,5 & 4 & 4 & 5 & 6 & 7 \\
\hline CL.4.1 & ADULTO MEDIO & $35-40$ & --- & --- & 35 & --- & --- & 7 & 6 & --- \\
\hline
\end{tabular}


Tabla 7. Representación de piezas dentales y modificaciones fisiológicas y patológicas de la cavidad bucal.

\begin{tabular}{|c|c|c|c|c|c|c|c|c|}
\hline & & \multicolumn{4}{|c|}{ REPRESENTACIÓN DE PIEZAS DENTALES } & \multicolumn{3}{|c|}{$\begin{array}{l}\text { MODIFICACIONES FISIOLÓGICAS Y } \\
\text { PATOLÓGICAS }\end{array}$} \\
\hline \multicolumn{2}{|c|}{ CAÑADÓN LEONA 5} & DIENTES & IN SITU & AISLADOS & PDPM & PDAM & ABSCESOS & PERIODNT \\
\hline CL.1.1 & $\begin{array}{l}\text { M. superior } \\
\text { Mandíbula }\end{array}$ & 16 & 16 & 0 & 0 & 0 & 0 & 0 \\
\hline CL.1.2 & $\begin{array}{l}\text { M. superior } \\
\text { Mandíbula }\end{array}$ & $\begin{array}{r}16 \\
-- \\
\end{array}$ & 6 & $\begin{array}{l}10 \\
--- \\
\end{array}$ & 0 & 0 & $\begin{array}{c}0 \\
--- \\
\end{array}$ & $\begin{array}{c}0 \\
--- \\
\end{array}$ \\
\hline CL.2.1 & $\begin{array}{l}\text { M. superior } \\
\text { Mandíbula }\end{array}$ & $\begin{array}{ll}-- \\
--\end{array}$ & -- & -- & -- & -- & -- & -- \\
\hline CL.2.2 & $\begin{array}{l}\text { M. superior } \\
\text { Mandíbula }\end{array}$ & -- & 0 & 0 & 8 & 7 & 0 & 4 \\
\hline CL.3 & $\begin{array}{c}\text { M. superior } \\
\text { Mandíbula }\end{array}$ & $\begin{array}{l}0 \\
-- \\
\end{array}$ & $\begin{array}{l}0 \\
--- \\
\end{array}$ & $\begin{array}{l}0 \\
-- \\
\end{array}$ & $\begin{array}{l}10 \\
-- \\
\end{array}$ & $\begin{array}{l}4 \\
-- \\
\end{array}$ & $\begin{array}{c}2 \\
--- \\
\end{array}$ & $\begin{array}{c}0 \\
--- \\
\end{array}$ \\
\hline CL.4.1 & $\begin{array}{c}\text { M. superior } \\
\text { Mandíbula }\end{array}$ & $\begin{array}{c}11 \\
4 \\
\end{array}$ & $\begin{array}{l}4 \\
1 \\
\end{array}$ & $\begin{array}{l}7 \\
3 \\
\end{array}$ & $\begin{array}{l}5 \\
6 \\
\end{array}$ & $\begin{array}{l}0 \\
2 \\
\end{array}$ & $\begin{array}{l}0 \\
0 \\
\end{array}$ & $\begin{array}{l}0 \\
0 \\
\end{array}$ \\
\hline CL. 4.2 & $\begin{array}{l}\text { M. superior } \\
\text { Mandíbula }\end{array}$ & $\begin{array}{l}2 \\
-- \\
\end{array}$ & $\begin{array}{l}0 \\
--- \\
\end{array}$ & $\begin{array}{l}2 \\
--- \\
\end{array}$ & 0 & $\begin{array}{l}0 \\
--- \\
\end{array}$ & $\begin{array}{c}0 \\
-- \\
\end{array}$ & 0 \\
\hline CL.4.3 & $\begin{array}{l}\text { M. superior } \\
\text { Mandíbula }\end{array}$ & $\begin{array}{l}5 \\
-- \\
\end{array}$ & $\begin{array}{c}0 \\
--- \\
\end{array}$ & $\begin{array}{c}5 \\
--- \\
-\end{array}$ & $\begin{array}{c}0 \\
--- \\
\end{array}$ & $\begin{array}{c}0 \\
--- \\
\end{array}$ & $\begin{array}{c}0 \\
--- \\
\end{array}$ & $\begin{array}{c}0 \\
--- \\
\end{array}$ \\
\hline TOTAL & & 54 & 27 & 27 & 29 & 13 & 2 & 4 \\
\hline
\end{tabular}

PDPM: dientes perdidos postmortem; PDAM: dientes perdidos antemortem; PERIODNT: alvéolos/ tabla alveolar con periodontitis; ---: sin elemento (maxilar superior o mandíbula).

a un desgaste excesivo, a la formación de un absceso complejo o a un trauma. Descartando las caries como probables causantes, se considera que las PDAM se produjeron por efecto de procesos fisiológicos extremos (desgaste severo y/o formación de abscesos originados también por el desgaste). La presencia de estas patologías y modificaciones fisiológicas se observaron en los individuos de más de 30 años (Fig. 12). Las prevalencias de las modificaciones patológicas y fisiológicas observadas (elevado grado de desgaste dental, presencia de PDAM, abscesos, periodontitis y ausencia de caries) son semejantes a las registradas en otros grupos cazadores recolectores del área (L'Heureux y Amorosi 2009; L'Heureux y Barberena 2008).

\section{CONSIDERACIONES FINALES}

Del contexto de excavación de Cañadón Leona 5 se infiere una modalidad de entierro que implica una inversión de energía en el cavado de una fosa en un lugar reparado y la preparación de los cuerpos con ocre para su inhumación (con ausencia de ajuar funerario). Las notas de excavación (Bird 1988) no mencionan la cobertura del entierro con algunos bloques de roca, pero si se tiene en cuenta la elevada frecuencia de daños mecánicos sobre las superficies óseas de los huesos $(13,27 \%)$ se puede inferir que por sobre los cuerpos se depositaron grandes piedras que generaron estas modificaciones. Esto se relaciona con lo observado en otros sitios en la región adyacente de Pali Aike con cronologías comparables como Cerro

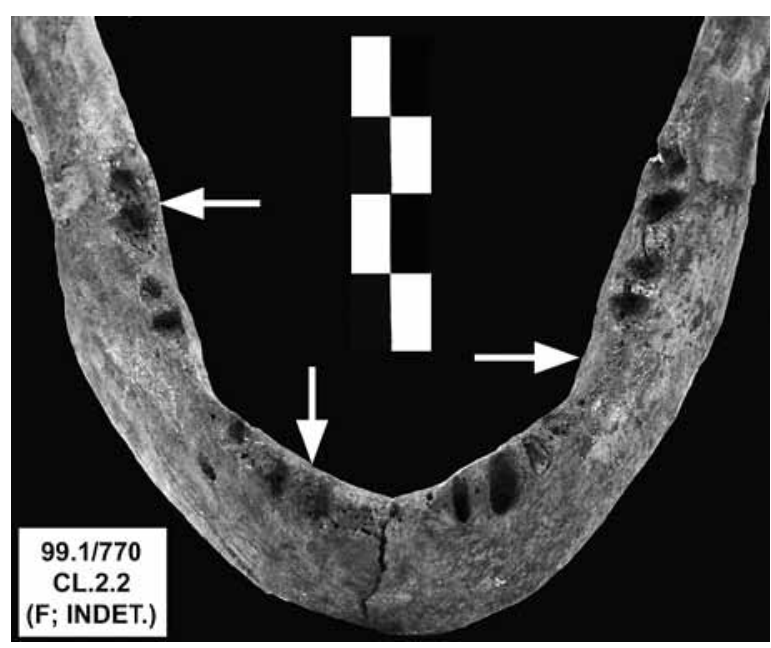

Fig. 12. Vista oclusal de la mandíbula de CL.2.2. Se aprecia la presencia de pérdidas dentales antemortem y la modificación del borde de la tabla alveolar con porosidad del hueso cortical a la altura de los terceros molares y del canino e incisivo derecho. 
Sota (L'Heureux y Amorosi 2009) y Orejas de Burro 1 (L'Heureux y Barberena 2008) donde la disposición confirmada de bloques directamente sobre los individuos generó frecuencias de daños mecánicos similares y hasta menores $(0,91 \%$ y $19,33 \%$ Cerro Sota y Orejas de Burro 1 respectivamente) sobre las superficies corticales de los huesos. Del mismo modo, en los materiales de Cañadón Leona 5 se observa la presencia de marcas de gramíneas $(2,66 \%)$ mostrando que los restos de los individuos CL.1.1, CL.1.2, CL.2.2 y CL. 3 tuvieron algún contacto con radículas por un tiempo prolongado a pesar de la ausencia de referencias contextuales que mencionen la presencia de un suelo vegetado en el sector del entierro.

Acerca de la información del estado de salud de los individuos, los resultados obtenidos sobre las modificaciones bucales se ajustan, en parte, con el modelo de Lukacs (1989) que postula para poblaciones cazadoras-recolectoras una alta prevalencia de desgaste dental severo y exposición de la cavidad pulpar por dicha causa y una baja frecuencia de caries y lesión periodontal. La diferencia radica en la presencia moderada de abscesos, periodontitis y pérdidas dentales antemortem. El modelo citado asocia las enfermedades periodontales con la prevalencia de caries (las primeras como efecto de las segundas), pero éstas también se pueden originar por procesos infecciosos originados por el desgaste dental severo en edades avanzadas.

En el resto del esqueleto la elevada prevalencia (por individuo) de enfermedades osteoartrósicas $(37,5 \%)$ puede asociarse con la exigencia física y el estrés ejercido sobre las articulaciones por estos cazadores-recolectores desde los 30 años de edad o antes. Por otro lado, llama la atención la presencia de dos individuos (25\%) adultos de 35 o más años de edad de diferente sexo con lesiones traumáticas craneales circulares y subcirculares producidas antemortem. Es sorprendente que estas lesiones pasaran por alto durante tanto tiempo, pero debe tenerse en cuenta que no se realizaron previos análisis de laboratorio (exceptuando aquellos dirigidos a la reconstrucción y consolidación de los materiales) sobre los esqueletos de Cañadón Leona. De otros entierros excavados por J. Bird (e.g. Cerro sota y Pali Aike) se publicaron las descripciones de los elementos que componen los individuos (Ch. Lester e I. Tattersall en Bird 1988), pero éstas descripciones no incluyeron el material de Cañadón Leona 5.
Se asume que estos traumas en CL2.1 y CL.3 son signos de un evento de violencia interpersonal dentro o entre grupos. Este evento de violencia habría provocado las heridas que ulteriormente desencadenaron la muerte de los dos individuos. Se conoce que el tipo de enfrentamiento intergrupal más común y más letal entre sociedades simples ocurrió bajo la modalidad de raids (emboscadas, incursiones sorpresivas), los cuales podían generar varias bajas en individuos de diferente sexo y edad (Gat 1999). El único antecedente para el área de violencia interpersonal en el Holoceno tardío se registra en la costa norte del estrecho de Magallanes. Se trata de un cráneo con una perforación con inclusión, donde el ápice de una punta de proyectil de obsidiana verde se encuentra incrustado en la sutura temporo-parietal derecha. Dicha lesión presenta reabsorción ósea (antemortem) y no comprometió la supervivencia del individuo (Constantinescu 2003).

A pesar que la prevalencia arqueológica y etnográfica de señales de violencia suelen ser mayores entre individuos masculinos (e.g. Andrushko et al. 2005; Lambert 1997; Walker 2001), en Cañadón Leona se hallan afectados ambos sexos en igual proporción. Esto concuerda con los resultados obtenidos en un estudio de violencia interpersonal en el valle inferior del río Negro (Patagonia septentrional Argentina) para momentos posteriores al 1.300 AP. (Gordón y Ghidini 2007), en el que las diferencias de señales de violencia entre sexos no fueron significativas. Esta situación puede relacionarse con el planteo etnográfico que indica que cuando las tensiones sociales aumentan, la violencia afecta ambos sexos (Gordón y Ghidini 2007).

Aunque resulta difícil derivar precisiones sobre el arma que produjo las lesiones, a partir del tipo de lesión ósea se puede inferir que las depresiones traumáticas mencionadas se produjeron por un fuerte impacto intencional en la cabeza con un material duro, romo y sin vértices cortantes. Si bien un mismo instrumento puede producir diversas alteraciones en el hueso según como se combinan las variables de fuerza, distancia, dirección y ángulo del contacto (Ubelaker 1991), la morfología circular y subcircular de los impactos observada hace pensar en bolas de boleadora esféricas pequeñas como el instrumento probablemente implicado, las cuales fueron halladas entre el stock de instrumentos líticos del sitio. La lesión registrada en CL.3 (depresión subcircular con 


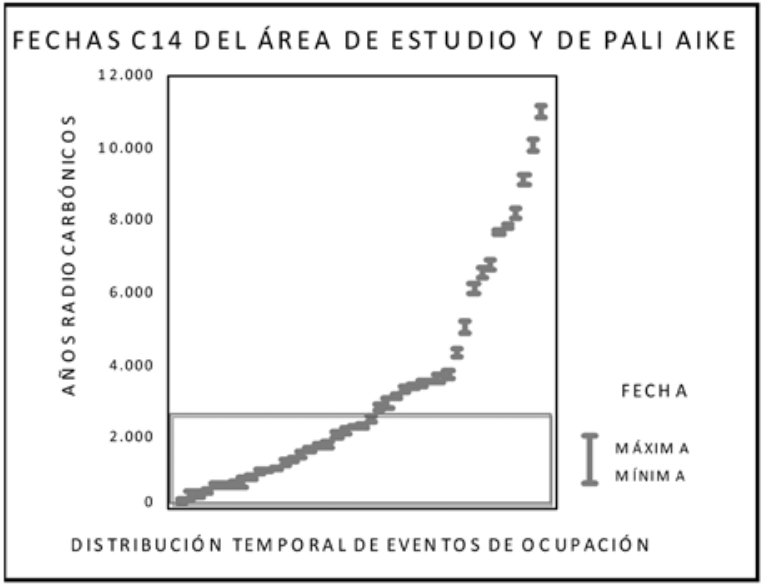

Fig. 13. Distribución temporal de eventos de ocupación en el área de estudio y en Pali Aike definidos a partir de 93 fechas radiocarbónicas no calibradas.

perforación asociada con una fractura con pérdida ósea), se ajusta con esta explicación por la depresión subcircular en el parietal superior izquierdo, aunque la fractura con osteoclastía que recorre todo este elemento y el temporal implica un tipo de lesión más compleja (Fig. 10).

Sin duda es necesario profundizar sobre el tema, pero la muerte contemporánea de dos individuos adultos de diferente sexo como consecuencia de un evento de violencia interpersonal, pone a este sitio arqueológico en un contexto de interés. Esto se debe a que, para la fecha estimada de uso y explotación de Cañadón Leona 5 (ca. 1.700-2.300 A.P.; Prieto et al. 1988), se infiere un incremento de la densidad poblacional significativa en la región comprendida entre los $51^{\circ} \mathrm{S}$ y el estrecho de Magallanes (Barberena 2008). El análisis de la distribución temporal de 93 fechados radiocarbónicos en la región de estudio (pampa de Magallanes) y áreas adyacentes (campo volcánico de Pali Aike), evidencia un aumento significativo en la ocupación y reutilización de este espacio (50-52 ${ }^{\circ}$ sur) durante el Holoceno tardío después del 2.500 AP. (Fig. 13).

Entre los tantos factores que pueden originar eventos de violencia interpersonal, con este caso de estudio se relaciona el incremento demográfico en un área circunscripta y la competencia por interferencia con otros grupos vecinos por territorios y recursos básicos (escasos?). Si bien la competencia o el incremento demográfico no serían por sí solos factores detonantes de situaciones de violencia, en condiciones sociales y/o ecológicas particulares (Barrientos y Gordón 2004) podría incrementarse la competencia por los recursos y por el espacio provocando un aumento de situaciones de tensión social y la propensión de eventos de violencia dentro y entre grupos vecinos en el área después del 2.500 AP. "En este sentido, el caso del individuo con deficiencia de hierro $(12,5 \%)$ podría abogar la hipótesis de tensión social por condiciones de escasez de alimentos si el origen de la hiperostosis porótica registrada en CL.1.2 fuera nutricional".

Para finalizar se considera que la nueva información obtenida de esta inhumación múltiple y simultánea a más de setenta años de su excavación, es una importante contribución al estudio de diferentes aspectos socioecológicos de los cazadores recolectores (e.g. demografía; violencia interpersonal), al conocimiento de las condiciones de salud (patologías) de estas poblaciones y al estudio regional de las prácticas mortuorias durante el Holoceno tardío en el área comprendida entre el oeste de la pampa de Magallanes y el sector noroccidental del estrecho homónimo.

\section{AGRADECIMIENTOS}

A Ian Tattersall y Gisselle García por permitirnos estudiar las muestras de los entierros excavados por Junius Bird depositadas en la Division of Anthropology, American Museum of Natural History (AMNH). A Alfredo Prieto y Susana Morano Büchner por cedernos gentilmente imágenes del material óseo humano de Cañadón Leona 5 depositado en el Centro de Estudios del Hombre Austral, Instituto de la Patagonia, Universidad de Magallanes. A University of Iowa Press (copyright holder) por otorgar el permiso para la reproducción de una de las imágenes del libro de J. Bird. A Luis Borrero por la lectura crítica del manuscrito. Este trabajo se realizó en el marco de la Pasantía Posdoctoral en el exterior del CONICET (Resolución D № 3351) otorgada a la primer autora.

\section{BIBLIOGRAFÍA CITADA}

\footnotetext{
ANDRUSHKO, V., K. LATHARN, D. GRADY, A. PASTOR y P. WALKER. 2005. Bioarchaeological evidence for trophy taking in prehistory central California. American Journal of Physical Anthropology 127:375-384.
} 
BARBERENA, R. 2008. Arqueología y biogeografía humana en Patagonia meridional. Sociedad Argentina de Antropología, Buenos Aires.

BARRIENTOS, G. y F. GORDÓN. 2004. Explorando la relación entre nucleamiento poblacional y violencia interpersonal durante el Holoceno tardío en el noreste de Patagonia (República Argentina). Magallania 32:53-69.

BIRD, J. 1988. Travels and archaeology in South Chile. Editado por J. Hyslop. University of Iowa Press, Iowa.

BROOKS, S. y J. SUCHEY. 1990. Skeletal Age Determination Based on the Os Pubis: A Comparison of the AcsádiNemeskéri and Suchey-Brooks Methods. Human Evolution 5:227-238.

BUIKSTRA, J. y D. UBELAKER (EDITORES). 1994. Standards for data collection from human skeletal remains. Arkansas Archaeological Survey Research Series 44, New York.

CLARKE, N. G. y R. S. HIRSCH. 1991. Tooth dislocation: The relationship with tooth wear and dental abscesses. American Journal of Physical Anthropology 85:293-298.

CONSTANTINESCU, F. 2003. Obsidiana verde incrustada en un cráneo Aónikenk: ¿tensión social intraétnica.... interétnica? We'll never know!. Magallania 31:149-153.

GAT, A. 1999. Pattern of fighting in simple, small-scale, pre state societies. Journal of Anthropological Research 55:563-583.

GORDÓN, F. y G. GHIDINI. 2007. Análisis bioarqueológico de la violencia interpersonal. El valle inferior del río Negro (República Argentina) durante el Holoceno tardío. Revista Werken 9:27-45.

HESSE, B. y P. WAPNISH. 1985. Animal bone archeology: From objectives to analysis. Teraxacum Inc., Washington.

HILDEBOLT, C. F. y S. MOLNAR . 1991. Measurement and Description of Periodontal Disease in Anthropological Studies. En Advances in Dental Anthropology, editado por M. Kelley y C. Larsen, pp. 225-240. Willey - Liss, New York.

LAMBERT, P. 1997. Patterns of violence in prehistoric huntergatherers societies of coastal southern California. En Troubles times: violence and warfare in the past, war and society, editado por D. L. Martin y D. W. Frayer. 6:77-109. Gordon and Beach Publishers, Amsterdam.

LAMING-EMPERAIRE, A. 1968. Le site Marassi en terre de Feu. Rehue 1:133-143.
L'HEUREUX, G. L. y R. BARBERENA. 2008. Evidencias bioarqueológicas en Patagonia meridional: el sitio Orejas de Burro 1 (Pali Aike, Pcia. de Santa Cruz). Intersecciones en Antropología 9:65-78.

L'HEUREUX G. L. y T. AMOROSI. 2009. El entierro del sitio Cerro Sota (Magallanes, Chile) a más de setenta años de su excavación. Enviado para su publicación a Magallania.

LUKACS, J. 1989. Dental paleopathology: methods for reconstructing dietary patterns. En Reconstruction of Life From the Skeleton, editado por M. Iscan y K. Kennedy, pp. 261-286. Alan R. Liss, Inc., New York.

MEINDL, R. S. y C. O. LOVEJOY. 1985. Ectocranial suture closure: a revised method for the determination of skeletal age at death based on the lateral anterior sutures. American Journal of Physical Anthropology 68: 57-66.

ORTNER, D. J. 2003. Identification of pathological conditions in human skeletal remains. $2^{\circ}$ edición. Elsevier, San Diego.

PRIETO, A., F. MORELLO, R. CÁRDENAS y M. CHRISTENSEN. 1998. Cañadón Leona: a sesenta años de su descubrimiento. Anales del Instituto de la Patagonia (Serie Ciencias Humanas) 26:83-105.

SCHUTKOWSKI, H. 1993. Sex determination on infant and juvenile skeletons: I. Morphognostic features. American Journal of Physical Anthropology 90: 199-205.

SCOTT, E. C. 1979. Dental wear scoring technique. American Journal of Physical Anthropology 51:213-218.

SMITH, B. H. 1984. Patterns of molar wear in hunter-gatherers and agriculturalists. American Journal of Physical Anthropology 63:39-56.

STEELE, G. y C. BRAMBLETT. 1988. The Anatomy and Biology of the Human Skeleton. Texas A\&M University Press. College Station. Texas.

TROTTER, M. 1970. Estimation of stature from intact long bones. En: Personal identification in Mass Disasters, editado por T. D. Stewart pp.71-83, National Museum of Natural History. Washington D. C.

UBELAKER, D. 1989. Human Skeletal Remains. Segunda edición. Taraxacum Press, Washington D. C.

-1991. Perimortem and postmortem modification of human bone. Lesson from forensic anthropology. Anthropologie XXIX/3.

WALDRON, T. 2009. Paleopathology. CambridgeManuals in Archaeology, Cambridge University Press. Cambridge.

WALKER, P. L. 2001. A bioarchaeological perspective on the history of violence. Annual Review of Anthropology 30:573-596. 
